\title{
Hypoxia Directs Human Extravillous Trophoblast Differentiation in a Hypoxia-Inducible Factor-Dependent Manner
}

\author{
Anna K. Wakeland, ${ }^{* \dagger}$ Francesca Soncin, ${ }^{* \dagger}$ Matteo Moretto-Zita, ${ }^{* \dagger}$ Ching-Wen Chang, ${ }^{* \dagger}$ Mariko Horii, ${ }^{* \dagger}$ Don Pizzo, ${ }^{*}$ \\ Katharine K. Nelson, ${ }^{* \dagger}$ Louise C. Laurent, ${ }^{\dagger \dagger}$ and Mana M. Parast ${ }^{* \dagger}$
}

From the Departments of Pathology* and Reproductive Medicine ${ }^{\ddagger}$ and the Sanford Consortium for Regenerative Medicine, ${ }^{\dagger}$ University of California San Diego, La Jolla, California

\author{
Accepted for publication \\ November 29, 2016. \\ Address correspondence to \\ Mana M. Parast, M.D., Ph.D., \\ Department of Pathology, San- \\ ford Consortium for Regenera- \\ tive Medicine, University of \\ California San Diego, 9500 \\ Gilman Dr, MC 0695, La Jolla, \\ CA 92093. E-mail: mparast@ \\ ucsd.edu.
}

\begin{abstract}
Villous cytotrophoblasts are epithelial stem cells of the early human placenta, able to differentiate either into syncytiotrophoblasts in floating chorionic villi or extravillous trophoblasts (EVTs) at the anchoring villi. The signaling pathways regulating differentiation into these two lineages are incompletely understood. The bulk of placental growth and development in the first trimester occurs under low oxygen tension. One major mechanism by which oxygen regulates cellular function is through the hypoxia-inducible factor (HIF), a transcription factor complex stabilized under low oxygen tension to mediate cellular responses, including cell fate decisions. HIF is known to play a role in trophoblast differentiation in rodents; however, its role in human trophoblast differentiation is poorly understood. Using RNA profiling of sorted populations of primary first-trimester trophoblasts, we evaluated the first stage of EVT differentiation, the transition from epidermal growth factor receptor ${ }^{+}$villous cytotrophoblasts into human leukocyte antigen $-\mathrm{G}^{+}$proximal column EVT (pcEVT) and identified hypoxia as a major pcEVT-associated pathway. Using primary cytotrophoblasts, we determined that culture in low oxygen directs differentiation preferentially toward human leukocyte antigen- $\mathrm{G}^{+}$pcEVT, and that an intact HIF complex is required for this process. Finally, using global RNA profiling, we identified integrin-linked kinase and associated cytoskeletal remodeling and adhesion to be among HIFdependent pcEVT-associated signaling pathways. Taken together, we propose that oxygen regulates EVT differentiation through HIF-dependent modulation of various cell adhesion and morphology-related pathways. (Am J Pathol 2017, 187: 767-780; http://dx.doi.org/10.1016/j.ajpath.2016.11.018)
\end{abstract}

Proper formation and function of the placenta is required for normal fetal growth and development in utero. ${ }^{1,2}$ Early development of the human placenta occurs under low oxygen conditions, during which time the placenta anchors itself to the uterus and establishes the maternal-fetal interface. ${ }^{3,4}$ Cytotrophoblasts (CTBs), the proliferative epithelial stem cells of the placenta, either fuse and form syncytiotrophoblasts (STBs) in the floating chorionic villi, which comprise the gas/nutrient exchange portion of the placenta, or differentiate into extravillous trophoblasts (EVTs), which subsequently invade the uterus and remodel maternal spiral arterioles to gain access to maternal blood. ${ }^{2,3}$ Differentiation of CTBs into EVTs occurs in the anchoring villi, and involves a multistep process. ${ }^{5}$ In the first step, villous CTBs, epidermal growth factor receptor $(\mathrm{EGFR})^{+}$cells adjacent to the villous mesenchyme, differentiate into human leukocyte antigen (HLA)-G ${ }^{+}$proximal column EVTs (pcEVTs), which remain proliferative. pcEVTs subsequently lose their proliferative potential in the distal column, and then mature into cells that invade the decidua and myometrium as either

Supported by California Institute for Regenerative Medicine (CIRM) New Faculty Award RN2-00931 (M.M.P.), CIRM Physician-Scientist Award RN3-06396 (M.M.P.), and NIH/National Institute of Child Health and Human Development grant R01-HD071100 (M.M.P.); CIRM Research and Training grant TG2-01154 to the University of California, San Diego (M.H.); and UC San Diego Respiratory Biology Training grant T32HL098062 (A.K.W.).

Disclosures: None declared. 
interstitial EVTs or endovascular EVTs. ${ }^{5}$ The latter remodel the maternal spiral arterioles, replacing endothelial cells, and thus taking control of maternal blood flow into the intervillous space. ${ }^{5,6}$

The above process of EVT differentiation takes place under low oxygen tension, ${ }^{4}$ although the maturation process is thought to occur in an increasing oxygen gradient, particularly for the endovascular EVT, which eventually accesses oxygen-rich spiral arterioles. ${ }^{6,7}$ How oxygen regulates these cells in the early placenta has been the subject of numerous studies. $^{7-12}$ Many hypoxia-induced signaling pathways act through the hypoxia-inducible factor (HIF) complex, a heterodimer formed from an $\alpha$ and a $\beta$ subunit. ${ }^{13}$ Multiple $\alpha$ subunits exist (including HIF $1 \alpha$ and HIF $2 \alpha$ ), each of which is stabilized in low oxygen, and subsequently translocate to the nucleus, where they bind to the constitutively expressed HIF1 $\beta$ subunit [alias aryl hydrocarbon receptor nuclear translocator (ARNT)] to form the transcriptionally active complex. ${ }^{13}$ The HIF complex is critical for embryonic development in mice, where loss of either HIF1 $\beta / A R N T$ or both of the main $\alpha$ subunits (HIF $1 \alpha / \mathrm{HIF} 2 \alpha$ ) leads to embryonic lethality at mid-gestation. ${ }^{14,15}$ The placental phenotypes associated with these transgenic animals include not just abnormal vascularization, but also abnormalities of the trophoblast. ${ }^{15,16}$ In fact, mouse trophoblast stem cells derived from either HIF $1 \alpha^{-1-} / \mathrm{HIF} 2 \alpha^{-1-}$ or $\mathrm{ARNT}^{-1-}$ embryos cannot form trophoblast giant cells, cells analogous to human EVTs, instead differentiating exclusively into multinucleated STBs. ${ }^{15,16}$ Similarly, HIF plays an important role in the development of the rat placenta, where hypoxia has been shown to promote both differentiation into trophoblast giant cells in vitro and trophoblast invasion of the uterus in vivo. ${ }^{17,18}$

In the human placenta, the role of hypoxia has been more controversial. ${ }^{19}$ However, this is at least in part because of mixed terminology, specifically, the use of the term cytotrophoblast for both villous CTB (vCTB) and at least some subtypes of EVT. ${ }^{6}$ For this reason, many reviews on this subject summarize conclusions from these studies as hypoxia inducing proliferation of CTB and inhibiting EVT differentiation. ${ }^{6,20-22}$ Moreover, the role of HIF in inducing the EVT lineage in the human placenta, as it does in rodents, also remains unclear. We therefore set out to further evaluate the initial transition of vCTB into pcEVT at the molecular level, including the effect of oxygen tension and HIF.

\section{Materials and Methods}

Isolation and Culture of Primary Cytotrophoblast from Human Placental Samples

All fetal and placental tissues were collected under a protocol approved by the Human Research Protections Program Committee of the University of California San Diego Institutional Review Board; all patients gave informed consent for collection and use of these tissues.
First-trimester trophoblasts were isolated from 6- to 9week (for microarray-based gene expression profiling experiments) or 8- to 10-week (for culture) gestational age placentas. Areas rich in chorionic villi were minced, washed in Hanks' balanced salt solution, and subjected to three sequential digestions: digestion $1,300 \mu \mathrm{g} / \mathrm{mL}$ of DNase I (10104159001; Roche, Pleasanton, CA) and $0.125 \%$ trypsin (Gibco, Carlsbad, CA); digestions 2 and 3, $0.25 \%$ trypsin and $300 \mu \mathrm{g} / \mathrm{mL}$ of DNase I. The pelleted cells from the second and third digests were pooled and resuspended in Hanks' balanced salt solution (Thermo Fisher Scientific, Carlsbad, CA), and separated on a Percoll (Sigma-Aldrich, St. Louis, MO) gradient. For optimization of cell plating, we used laminin $(50 \mu \mathrm{g} / \mathrm{mL}$; Santa Cruz Biotechnologies, Santa Cruz, CA), collagen IV ( $8 \mu \mathrm{g} /$ $\mathrm{cm}^{2}$; Sigma-Aldrich), and fibronectin $(20 \mu \mathrm{g} / \mathrm{mL}$; SigmaAldrich). For the remaining experiments, fibronectin was used for plating. Cells were cultured in media containing Dulbecco's modified Eagle's medium/F12 (Gibco), 10\% fetal bovine serum (Sigma-Aldrich), containing penicillinstreptomycin (Thermo Fisher Scientific), and gentamicin (Gibco) for 4 days. For hypoxic culture, cells were incubated at $2 \%$ oxygen in an XVIVO system (Biospherix, Parish, NY). For all experiments in hypoxia, medium was changed and cells were lysed (for either RNA or protein analysis) or fixed (for immunofluorescence and flow cytometry) in the XVIVO work chamber.

\section{Constructs for Down-Regulation of ARNT}

The vector consisting of a pLKO.1 lentiviral backbone containing a negative control (scramble) shRNA sequence was obtained from Addgene (Cambridge, MA). A set of five Mission shRNA Lentiviral constructs (also built using the pLKO.1 backbone) targeting the human ARNT gene were purchased (Sigma-Aldrich). HEK293FT cells were transfected with the shRNA constructs, Delta 8.2, and VSV-G using Lipofectamine 2000 (Sigma-Aldrich), according to the manufacturer's instructions. Lentiviral supernatants were concentrated with PEG-it virus precipitation solution (System Biosciences, Mountain View, CA). The concentrated viral particles were then incubated with target cells in the presence of $10 \mathrm{mg} / \mathrm{mL}$ polybrene (Sigma-Aldrich). Packaging and transduction efficiency were tested using a green fluorescent protein-expressing lentivirus in parallel experiments. Of the five ARNT-specific shRNA constructs, three were selected for further experiments on the basis of high-efficiency knockdown of ARNT protein levels in HEK293T cells; subsequent experiments were performed with this subset of three shRNAs pooled together. Isolated primary CTBs were transiently transduced at the time of plating. Transduction efficiency was determined by green fluorescent protein expression. Knockdown efficiency was determined by Western blot. 


\section{Immunofluorescence Staining of Tissues and Cells}

Placental tissue was fixed overnight in formalin, paraffin embedded, and cut into sections ( $4 \mu \mathrm{m}$ thick). Sections were deparaffinized and rehydrated, and antigen retrieval was performed in citrate buffer. Sections were blocked in $10 \%$ fetal bovine serum and $0.5 \%$ fish gelatin and stained with rabbit anti-EGFR antibody (Santa Cruz Biotechnologies) and mouse anti-HLAG antibody (clone 4H84; Abcam, Cambridge, MA), followed by Alexa 488- or Alexa 596-conjugated secondary antibodies (Invitrogen, Carlsbad, CA). Stained tissue was imaged using a Leica DM IRE2 inverted fluorescence microscope (Leica Microsystems Inc, Buffalo Grove, IL).

Cultured cells were fixed in $4 \%$ paraformaldehyde in phosphate-buffered saline for 10 minutes, then permeabilized with $0.5 \%$ Triton X-100 for 2 minutes. Cells were stained with mouse anti-HLAG antibody (clone 4H84; Abcam), rabbit anti-Ki-67 antibody (Abcam), or Alexa 488-conjugated phalloidin (Invitrogen), counterstained with DAPI (Invitrogen), then visualized using a Leica DM IRE2 inverted fluorescence microscope. For determination of fusion index, nuclei and cells were counted in five randomly selected $10 \times$ objective fields per condition. Cell fusion was quantitated as a fusion index of $(\mathrm{N}-\mathrm{S}) / \mathrm{T}$, where $\mathrm{N}$ is the number of nuclei in the syncytia, $\mathrm{S}$ is the number of syncytia, and $\mathrm{T}$ is the total number of nuclei counted.

\section{Flow Cytometry and Fluorescence Activated Cell Sorting}

For flow cytometric analysis, cells were fixed with 4\% paraformaldehyde. Cells were incubated with phosphatidylethanolamine-conjugated mouse anti-HLA-G (MEM-G/9; ExBio, Vestec, Czech Republic) and Allophycocyanin-conjugated mouse anti-EGFR (BioLegend, San Diego, CA) antibodies at room temperature for an hour, washed, and resuspended in an appropriate volume of fluorescence activated cell sorting buffer $(1 \times$ phosphatebuffered saline, $10 \%$ fetal bovine serum). Flow cytometric analysis was performed using a BD FACS-Canto Flow Cytometer (BD Biosciences, San Jose, CA).

To obtain the populations of sorted CTBs or sorted EVTs, freshly isolated first-trimester trophoblasts were stained with phosphatidylethanolamine-conjugated mouse anti-HLA-G (87G; Biolegend) and Allophycocyanin-conjugated mouse anti-EGFR (BioLegend) and sorted using a BD Influx instrument (BD Biosciences).

\section{Automated ISH and IHC}

For both in situ hybridization (ISH) and immunohistochemistry (IHC), placental tissue samples were fixed in neutral-buffered formalin, embedded in paraffin, and cut into sections ( $4 \mu \mathrm{m}$ thick). Both procedures were performed on a Ventana Discovery Ultra automated stainer (Ventana Medical Systems, Tucson, AZ).

For ISH, slides were deparaffinized, and subjected to antigen retrieval and protease treatment as described by the manufacturer (ACD-Bio, Hayward, CA). ISH was performed using the RNAscope method with probes specific to human TEAD2, GCM1, HIF1A, and ASCL2, all from ACD-Bio. Probes consisted of the z-DNA method, where two adjacent 18- to 25-bp probes hybridize to the mRNA sequence. ${ }^{23}$ The z-DNA probe has a 14-bp linker region and an adjacent 25-bp sequence; when two z-pairs hybridize next to each other, they contain a 50-bp backbone to which a subsequent probe and amplifier sequence hybridize. This allows for up to 8000 labels for each target mRNA. ${ }^{23}$ After amplification steps, the probes were visualized with 3,3'-diaminobenzidine and slides were counterstained with hematoxylin. Each of the probes used in the study were tested in tissues where their expression level and pattern could be readily validated. Both negative (bacterial dapB mRNA) and positive control probes (cyclophilin PPIB mRNA) were used on selected tissues to ensure probe specificity. Each dot corresponds to a single RNA message (mRNA); larger dots may be multiple mRNAs closely localized.

For IHC, placental sections were stained with a rabbit monoclonal antibody against HIF1A (final dilution of 1:225; CellMarque, Rocklin, CA) or with a rabbit polyclonal antibody against integrin-linked kinase 1 (ILK1; final dilution of 1:75; Cell Signaling, Danvers, MA). Antigen retrieval was performed using Cell Conditioning 1 solution (Ventana Medical Systems) for 40 minutes at $95^{\circ} \mathrm{C}$. The primary antibodies were incubated on the sections for 1 hour at $37^{\circ} \mathrm{C}$. Primary antibodies were visualized using $3,3^{\prime}-$ diaminobenzidine as a chromagen using the UltraMap system (Ventana Medical Systems), followed by hematoxylin as a counterstain. Slides were rinsed, dehydrated through alcohol and xylene, and coverslipped.

Both ISH and IHC slides were analyzed by conventional light microscopy on an Olympus BX43 microscope (Olympus, Waltham, MA).

\section{Western Blot Analysis}

After washing with ice-cold phosphate-buffered saline, cells were scraped in lysis buffer containing $1 \%$ Triton X-100 and $0.5 \% \mathrm{SDS}, 150 \mathrm{mmol} / \mathrm{L} \mathrm{NaCL}$ in $50 \mathrm{mmol} / \mathrm{L}$ Tris, $\mathrm{pH} 7.5$, with $100 \times$ HALT protease inhibitor cocktail (Thermo Fisher Scientific), and 100× EDTA (Thermo Fisher Scientific). Samples were sonicated for 15 seconds at $20 \%$ amplitude, spun at $15,000 \times g$ for 10 minutes to pellet any insoluble material, and the supernatant was collected. The protein concentration of each sample was determined using a BCA protein assay reagent (Thermo Fisher Scientific). Samples were mixed with $10 \times$ SDS-PAGE sample buffer $(20 \mathrm{mmol} / \mathrm{L}$ Tris, $\mathrm{pH} 8.0$, $2 \% \mathrm{SDS}, 2 \mathrm{mmol} / \mathrm{L}$ dithiothreitol, $1 \mathrm{mmol} / \mathrm{L} \mathrm{Na} \mathrm{VO}_{4}, 2$ $\mathrm{mmol} / \mathrm{L}$ ethylenediamine tetraacetic acid, and $20 \%$ glycerol) plus 5\% 2-mercaptoethanol (Bio-Rad, Hercules, CA) and 
boiled for 10 minutes. Total cellular protein $(30 \mu \mathrm{g})$ was separated by $10 \%$ SDS-PAGE and then transferred to polyvinylidene difluoride membranes. The membranes were blocked for 1 hour at room temperature in $20 \mathrm{mmol} / \mathrm{L}$ Tris, $\mathrm{pH}$ $8.0,150 \mathrm{mmol} / \mathrm{L} \mathrm{NaCl}$, and $0.05 \%$ Tween 20 (Thermo Fisher Scientific) containing 5\% nonfat dried milk (Bio-Rad). The membranes were then incubated with the primary antibody overnight at $4^{\circ} \mathrm{C}$. Primary antibodies included mouse antiARNT (BD Biosciences), rabbit anti-HIF1 $\alpha$ (Cayman Chemical, Ann Arbor, MI), mouse anti-HLAG (Novus Biologicals, Littleton, CO), rabbit anti-cleaved caspase 3 (Cell Signaling), mouse anti- $\beta$-actin (Sigma-Aldrich), and rabbit anti-ILK (BethylLab, Montgomery, TX). After three washes in $1 \mathrm{X}$ Tris-buffered saline containing $0.1 \%$ Tween, the membranes were incubated with the appropriate horseradish peroxidase-conjugated secondary antibodies (Jackson Immunoresearch, West Grove, PA) for 1 hour at room temperature, then washed with $1 \mathrm{X}$ Tris-buffered saline containing $0.1 \%$ Tween three times. The labeled proteins were visualized using the enhanced chemiluminescence kit (Thermo Fisher Scientific).

\section{Measurement of Secreted Total hCG and MMP2}

Cell culture supernatants were collected and stored in $-80^{\circ} \mathrm{C}$. Levels of total human chorionic gonadotropin (hCG) were quantified using the hCG ELISA Kit (Calbiotech Inc., Spring Valley, CA), according to the manufacturer's protocol. Levels of secreted matrix metalloproteinase 2 (MMP2) were quantified using MMP2 ELISA kit (Abcam). The results were normalized to DNA content, using DNA isolated from the DNEasy Blood and Tissue Kit (Qiagen, Valencia, CA).

\section{RNA Isolation, RT-qPCR, and Microarray-Based Gene Expression Profiling}

Total RNA was extracted with the mirVana RNA Isolation Kit (Ambion, Austin, TX), according to the manufacturer's protocol. For quantitative RT-PCR (RT-qPCR), purity and concentration of the samples were assessed with NanoDrop ND-1000 Spectrophotometer (Thermo Fisher Scientific). cDNA was prepared from 500 ng RNA using iScript (Bio$\mathrm{Rad}$ ) in a $20 \mu \mathrm{L}$ reaction, and diluted 1:5 with nuclease-free water. RT-qPCR was performed using $4 \mu \mathrm{L}$ of the diluted cDNA, along with $625 \mathrm{nmol} / \mathrm{L}$ of each primer and POWER SYBR Green PCR master mix (Applied Biosystems, Foster City, CA) in a total reaction volume of $20 \mu \mathrm{L}$. RT-qPCR was performed using a System 7300 instrument (Applied Biosystems) and a one-step program: $95^{\circ} \mathrm{C}, 10$ minutes; $95^{\circ} \mathrm{C}, 30$ seconds, $60^{\circ} \mathrm{C}, 1$ minute, for 40 cycles. Relative mRNA expression levels were determined by the $\Delta \Delta \mathrm{C}_{\mathrm{T}}$ method using 18S rRNA as a housekeeping gene and normalized to day 0 unless otherwise stated. Data are shown as relative mRNA expression with SD. All primer pairs (Table 1) were checked for specificity using BLAST
Table 1 List of qPCR Primers

\begin{tabular}{ll}
\hline Gene name & Primer sequence \\
\hline 18S & F: 5'-CGCCGCTAGAGGTGAAATTCT-3' \\
RCM1 & R: 5'-CGAACCTCCGACTTTCGTTCT-3' \\
& F: 5'-CTCGCAGAGGAGGGGCGCAA-3' \\
TEAD2 & R: 5'-ATAAAGCGTCCGTCGTGCCTCC-3' \\
& F: 5'-CAGGCCTCTGAGCTTTTCCA-3' \\
ASCL2 & R: 5'-GGAGGTCAGTAGATGGGGGA-3' \\
& F: 5'-CACTGCTGGCAAACGGAGAC-3' \\
EGFR & R: 5'-AAAACTCCAGATAGTGGGGGC-3' \\
HLA-G & F: 5'-CTAAGATCCCGTCCATCGCC-3' \\
& R: 5'-GGAGCCCAGCACTTTGATCT-3' \\
HIF1A & F: 5'-CAGATACCTGGAGAACGGGA-3' \\
TPM1 & R: 5'-CAGTATGATCTCCGCAGGGT-3' \\
& F: 5'-CGGCGCGAACGACAAGAAAAA-3' \\
IGFBP3 & R: 5'-TCCAGAAGTTTCCTCACACGC-3' \\
& F: 5'-TCATCATTGAGAGCGACCTG-3' \\
& R: 5'-TTAATTGTTCTTCCAGCTGTCG-3' \\
\hline
\end{tabular}

$F$, forward; $q P C R$, real-time quantitative $P C R$; $R$, reverse.

analysis and melting curve to ensure amplification of a single product with the appropriate size and melting temperature.

For RNA to be used for gene expression microarray, total RNA was purified using the MirVana RNA Isolation Kit (Ambion), quantified using the Ribogreen reagent (Lifetech, Inc., Carlsbad, CA) and a Qubit fluorometer (Thermo Fisher Scientific), and quality controlled on an Agilent 2100 Bioanalyzer (Agilent, Santa Clara, CA). Only those RNA samples with an RNA integrity number $>8.0$ were subjected to further gene expression analysis. Total input RNA (200 ng) was amplified and labeled using the TotalPrep kit (Ambion). The labeled product was then hybridized to Illumina HT12 arrays and scanned on a BeadArray Reader (Illumina, Inc., San Diego, CA), according to the manufacturer's instructions.

\section{Analysis of Gene Expression Profiling Data}

Probes were filtered with a detection $P$ value cutoff of 0.01 , and normalized by using the LUMI package in $\mathrm{R}$ with the robust spline normalization method. Qlucore Omics Explorer software version 3.1 (Qlucore AB, Lund, Sweden) was used to explore and analyze microarray gene expression data sets and to generate heat maps. Sorted vCTB $\left(\mathrm{EGFR}^{+}\right)$ and pcEVT $\left(\mathrm{HLAG}^{+}\right)$gene expression profiles were compared and specific gene signatures were defined with a variance $<0.01$, two-group comparison (equivalent to paired $t$-test) $\mathrm{q}<0.05$ and fold change $(\mathrm{FC}) \geq 1.5$. These specific gene signature lists were then subjected to Gene Ontology analysis using Metascape web application (http:// metascape.org, last accessed November 9, 2016) and signaling pathway analysis using Qiagen's Ingenuity Pathway Analysis (IPA; Qiagen, Redwood City, CA). 
Separately, expression profiles of freshly isolated vCTBs, and Scramble and sh-ARNT transduced vCTBs, cultured for 4 days in either $2 \%$ or $20 \%$ oxygen were also compared. Statistically significant genes were defined by variance $<0.01$, multigroup comparison (equivalent to analysis of variance) $\mathrm{q}<0.05$ and $\mathrm{FC} \geq 1.3$. To look at the effect of ARNT knockdown, probes specifically up-regulated in hypoxia in Scramble shRNA-treated cells were compared to probes up-regulated in hypoxia in ARNT shRNA-treated cells. The resulting groups were then compared to the gene signatures of sorted vCTBs and pcEVTs (as explained above). For this comparison, we used probes that had an FC of 1.3 or higher for cultured $\mathrm{vCTBs}$, or an $\mathrm{FC}$ of 2.0 or higher for the sorted vCTB and pcEVT samples.

The list of probes up-regulated in hypoxia in Scramble samples but not in shARNT samples was then subjected to Gene Ontology analysis using Metascape and signaling pathway analysis in IPA. Probe lists, with FC data, are provided in Supplemental Tables S1-S3.

All microarray data were submitted to the Gene Expression Omnibus repository (http://www.ncbi.nlm.nih.gov) with the accession numbers GSE80996 (for sorted vCTB and pcEVT)and GSE80995 (for freshly isolated vCTB, and vCTB transduced with Scramble and ARNT-specific shRNA and cultured for four days).

\section{Statistical Analysis}

Unless otherwise stated, data presented are means \pm SD of five separate first-trimester placentas. Paired $t$-test was performed, and $P$ values $<0.05$ were taken to indicate a statistically significant difference between the populations sampled.

\section{Results}

Isolation and Characterization of vCTB and pcEVT from First-Trimester Human Placenta

Immunostaining of first-trimester human placentas with EGFR and HLAG antibodies confirmed that vCTBs are characterized by EGFR, whereas proximal column extravillous trophoblasts (pcEVTs) are characterized by surface expression of HLA-G (Figure 1A). Placenta samples, aged 6
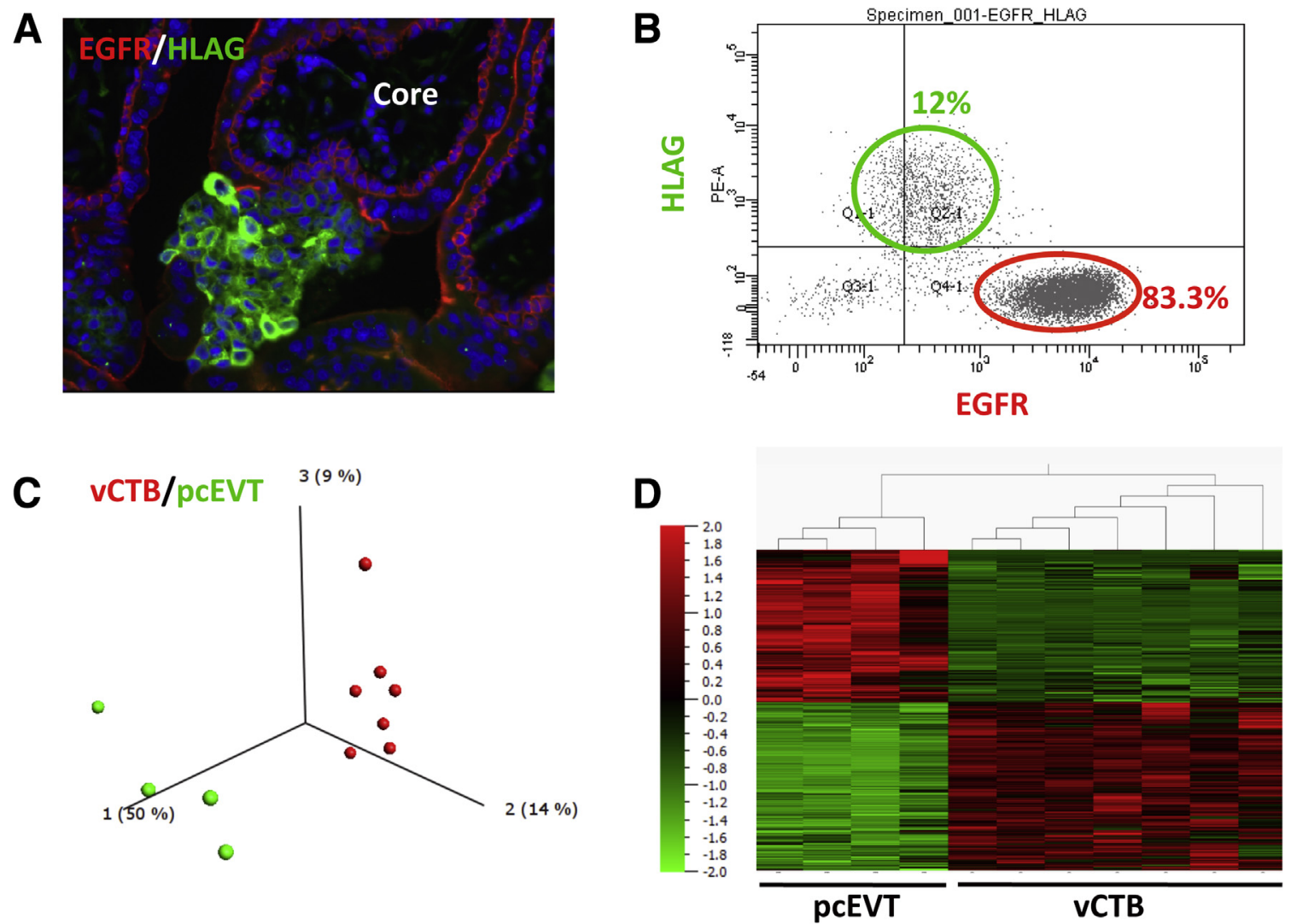

Figure 1 Characterization of the first step of villous cytotrophoblast ( $v C T B$ ) differentiation into a distinct proximal column extravillous trophoblast (pcEVT) population. A: Immunohistochemistry of first-trimester placenta showing epidermal growth factor receptor (EGFR) expression (red) in vCTB and human leukocyte antigen (HLA)-G expression (green) in pcEVT. Core indicates mesenchymal villous core. B: Representative flow cytometric analysis of freshly isolated

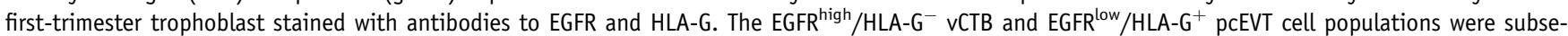
quently purified to $>99 \%$ by fluorescence activated cell sorting. C: After microarray-based gene expression profiling, principle component analysis shows separation, on the basis of the first principal component, of the sorted pcEVT (green) and vCTB (red) subpopulations. D: Hierarchical clustering shows distinct clusters of genes up-regulated in pcEVTs and vCTBs $(v<0.01$, two group comparison $q<0.05$, fold change $\geq 1.5)$. Original magnification, $\times 315(\mathbf{A})$. PE, phycoerythrin. 
to 9 weeks, were subjected to three steps of trypsin digestion (Materials and Methods), and the released single cells were immediately stained with EGFR and HLAG antibodies and subjected to fluorescence activated cell sorting. Analysis by flow cytometry confirmed that in this gestational age range, the trophoblasts are composed of two subpopulations: a larger (80\% to $90 \%$ ) $\mathrm{EGFR}^{\text {high }} / \mathrm{HLAG}^{-}$ $\mathrm{vCTB}$ population and a

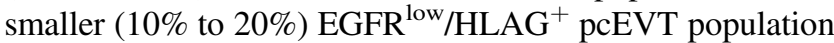
(Figure 1B). Seven separate placentas were subjected to the above cell isolation and sorting, followed by RNA isolation directly from the sorted cells; in three cases, RNA from the pcEVT samples was of insufficient quality (RNA integrity number $<7.0$ ) to be used for further analysis, so we proceeded to microarray analysis with the remaining seven vCTB samples and four pcEVT preparations. After data preprocessing, principal component analysis showed distinct clustering of these two cell populations (Figure 1C). Statistical analysis (Materials and Methods) revealed clusters of genes highly expressed in each cell population, representing distinct gene signatures for vCTBs (1733 gene probes) and pcEVTs (1546 gene probes) (Figure 1D and Supplemental Tables S1 and S2). We analyzed each gene signature for gene ontology $(\mathrm{GO})$ and signaling pathways, using Metascape and IPA, respectively. Supplemental Figure $\mathrm{S} 1$ shows the most highly enriched 10 GO and signaling pathways in $\mathrm{vCTB}$ and pcEVT, respectively. For vCTB, the most highly enriched GO categories and signaling pathways were related to cellular metabolism, protein ubiquitination, and the cell cycle. For pcEVT, the most highly enriched GO categories and signaling pathways included those involved in hypoxia, cytoskeletal remodeling, cell-cell and cell-matrix junctions, and interferon $\gamma$ signaling.

\section{Transcription Factors Up-Regulated in pcEVT}

We next evaluated the transcription factors (TFs) significantly up-regulated ( $\mathrm{v}<0.01$, q value $<0.05, \mathrm{FC} \geq 1.5$ ) in pcEVTs compared to vCTBs (Table 2). The most highly up-regulated TF was ASCL2 (12.4-fold), followed by TEAD2 (11.5-fold). Other transcription factors that were significantly up-regulated in pcEVTs included TCF4 and STAT4 (4.1-fold), HEY1 (3.8-fold), and HIF1A (2.6- and 2.4-fold for two different probes); these TFs have been

Table 2 List of Most Highly Up-Regulated Transcription Factors in $\mathrm{PcEVT}$

\begin{tabular}{ll}
\hline Gene name & Fold change in pcEVT/vCTB \\
\hline ASCL2 & 12.4 \\
TEAD2 & 11.5 \\
TCF4 & 4.1 \\
STAT4 & 4.1 \\
HEY1 & 3.8 \\
HIF1A & 2.6 \\
HIF1A & 2.4 \\
GCM1 & 1.8
\end{tabular}

pcEVT, proximal column extravillous trophoblast; vCTB, villous cytotrophoblast. previously associated with EVT. ${ }^{5,10}$ GCM1, a TF usually associated with differentiation of STB, was also significantly up-regulated in pcEVT (1.8-fold). We measured expression of ASCL2, TEAD2, HIF1A, and GCM1 in three independent samples each of $\mathrm{vCTB}$ and pcEVT by RT-qPCR (Figure 2A), and were able to confirm up-regulation of these TFs in pcEVT. To further validate the up-regulation and localization of these TFs in pcEVT, we performed in situ hybridization on first-trimester placental
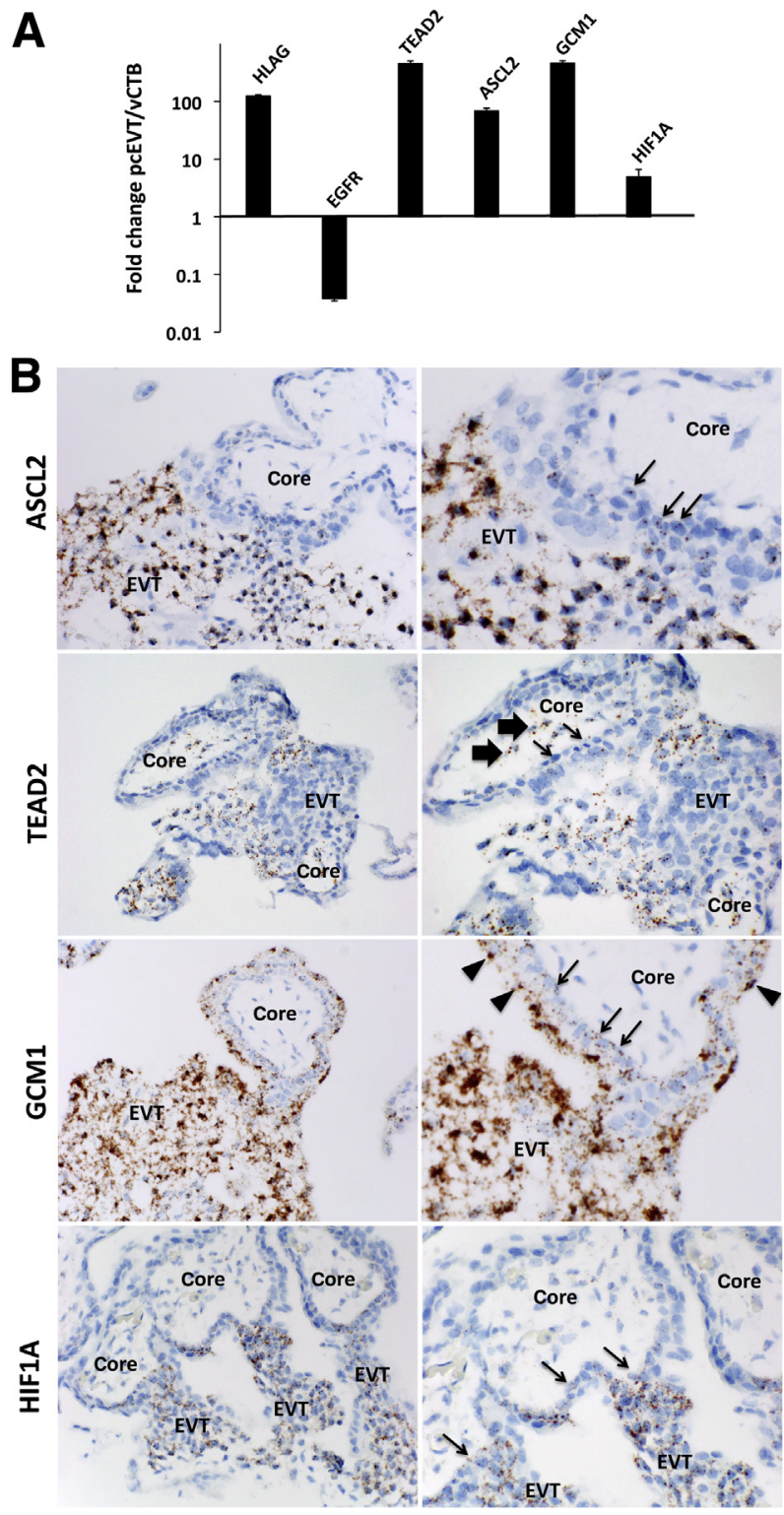

Figure 2 Validation of gene expression profiling. A: Quantitative RT-PCR analysis of the indicated genes in RNA extracted from sorted proximal column extravillous trophoblast ( $\mathrm{pcEVT}$ ) and villous cytotrophoblast (vCTB). B: In situ hybridization for the indicated genes in firsttrimester placental tissues. Each dot corresponds to a single mRNA; larger dots may be multiple mRNAs closely localized. Villous core and EVT are labeled; VCTB are highlighted by thin arrows, villous core cells by thick arrows, and syncytiotrophoblast by arrowheads. Original magnification: $\times 200$ (B, left column); $\times 300$ (B, right column). 
tissues using gene-specific probes (Figure 2B). All three gene products were abundantly found in pcEVTs, compared to vCTBs. Rare ASCL2 and HIF1A transcripts were also noted in vCTB near cell columns, whereas TEAD2 transcripts were also noted in vCTB and villous stromal cells (Figure 2B). GCM1 transcripts were also present in both vCTBs and STBs, although expression in vCTBs appeared significantly lower than in either STBs or pcEVTs (Figure 2B). We confirmed expression of HIF1A at the protein level in scattered EVTs (Supplemental Figure S2); however, we were unable to obtain specific antibodies to the other three transcription factors to use in IHC.

\section{Culture in Low 0xygen Tension Increases Differentiation of Isolated CTBs into pcEVTs}

Interestingly, hypoxia was noted as the top third group of GO terms most enriched in pcEVTs (Supplemental Figure S1). We therefore evaluated the effect of hypoxia on this initial transition of vCTBs into HLA-G ${ }^{+}$pcEVTs. For all these experiments, to minimize contamination with pcEVTs, we used 8- to 10-week gestation placentas and only proceeded when the preparations contained $>88 \%$ $\mathrm{EGFR}^{\text {high }} / \mathrm{HLAG}^{-} \mathrm{vCTBs}$ at the time of isolation.

We initially tested plating of these cells on fibronectin, collagen IV, and laminin, and found that isolated CTBs adhered to all but laminin-based matrices (Supplemental Figure S3). We tested differentiation of CTBs in $20 \%, 5 \%$, or $2 \%$ oxygen on both fibronectin- and collagen IV-coated dishes, and found that lowering oxygen tension increased the proportion of $\mathrm{HLA}_{-} \mathrm{G}^{+}$EVTs on both of these matrices (Supplemental Figure S3). We chose fibronectin for the remainder of the experiments, because this matrix is most commonly used for studying EVT differentiation. ${ }^{5,24} \mathrm{We}$ also chose to go forward with $2 \%$ oxygen in the remaining experiments as this gave the maximal response of EVT differentiation, on the basis of proportion of $\mathrm{HLA}-\mathrm{G}^{+}$cells.

We found that culture in $2 \%$ oxygen reproducibly resulted in a 1.5 -fold increase in proportion of surface $\mathrm{HLA}_{-} \mathrm{G}^{+}$ cells (Figure 3A). In fact, HLA-G protein was induced as early as day 1 after plating, along with stabilization of HIF1A protein (Supplemental Figure S4, A and B); no Ki$67^{+}$cells were noted in either condition, even early after plating (Supplemental Figure S4C). Induction of HLA-G in $2 \%$ oxygen was accompanied by increased levels of MMP2 secretion, another marker of $\mathrm{pcEVT}^{25}$ (Figure 3B), and decreased hCG secretion, a marker of STB (Figure 3C). We also noted decreased formation of syncytiotrophoblasts in $2 \%$ oxygen (Figure 3D). Finally, we assessed the effect of low oxygen tension on CTB differentiation by RT-qPCR for pcEVT-specific markers, including HLAG, ASCL2, and TEAD2, all of which were significantly higher at $2 \%$
A
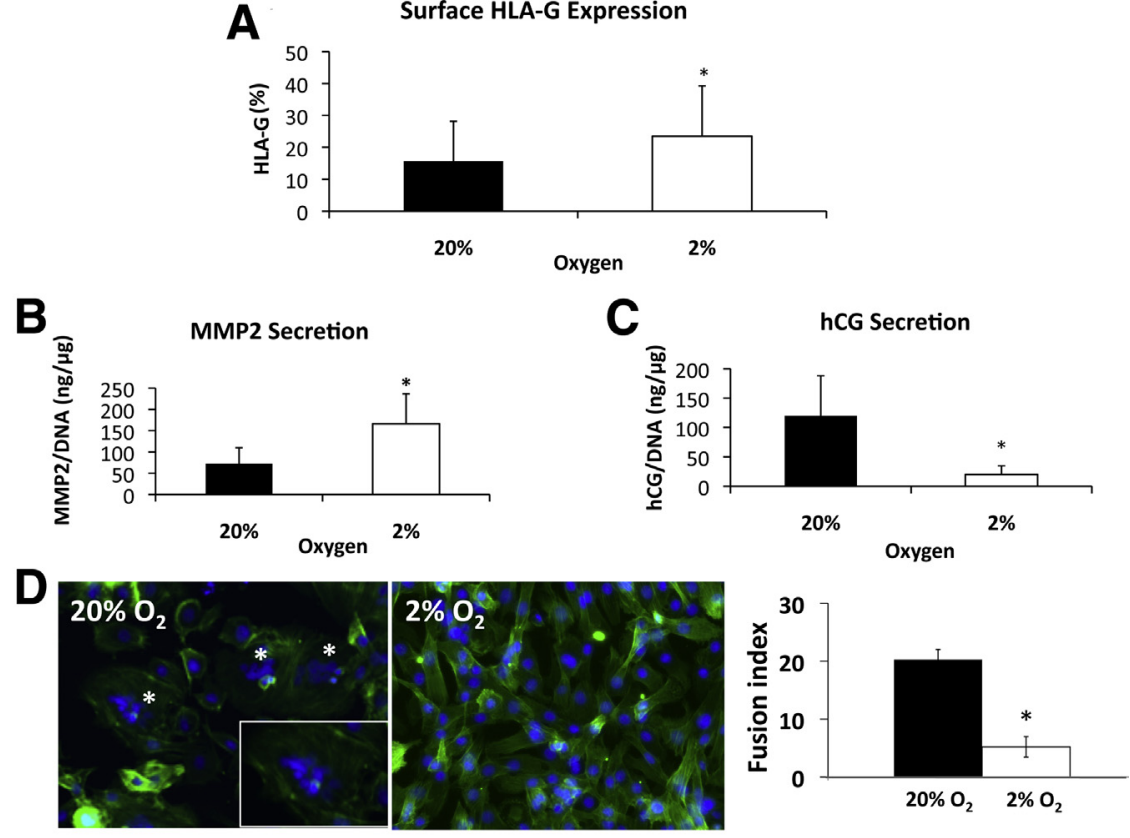

E
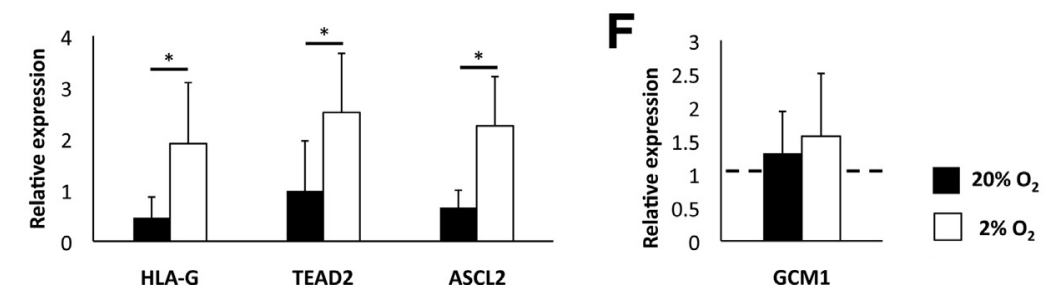

Figure 3 Effect of hypoxia on differentiation of villous cytotrophoblast (vCTB) into proximal column extravillous trophoblast ( $p c E V T$ ). A: Proportion of surface human leukocyte antigen (HLA)- $\mathrm{G}^{+}$cells after 4 days of culture in $20 \%$ or $2 \% 0_{2}$. B: Matrix metalloproteinase 2 (MMP2) secretion of VCTB cultured in $20 \%$ or $2 \% \mathrm{O}_{2}$, normalized to DNA content. C: Human chorionic gonadotropin (hCG) secretion of first-trimester vCTB cultured in $20 \%$ or $2 \% \mathrm{O}_{2}$, normalized to DNA content. D: Cultured vCTB after 4 days of culture in either $20 \%$ or $2 \%$ oxygen, stained with phalloidin (green) and DAPI (blue). Multinucleated syncytiotrophoblast are noted by asterisks; one syncytiotrophoblast is shown at higher magnification in the inset. Fusion index is shown graphically. E and F: Quantitative RT-PCR analysis of pcEVT-associated genes (E) and GCM1 (F) in VCTB cultured in $20 \%$ or $2 \% \mathrm{O}_{2}$. Values adjusted to freshly isolated (day 0 ) cells and normalized to $18 \mathrm{~S}$ ribosomal RNA. Dotted line in $\mathbf{F}$ represents value in freshly isolated (day 0 ) cells. $n=3$ (D); $n=5$ (E and $\mathbf{F}) .{ }^{*} P<0.05$. Original magnifications: $\times 100$ (D, main images) $; \times 200($ D, inset). 
oxygen (Figure 3E). Interesting, HIF1A also increased at the RNA level under $2 \%$ oxygen (Supplemental Figure S4D). Levels of GCM1 mRNA, confirmed to be highly expressed by in situ hybridization in both pcEVTs and STBs, compared to vCTBs (Figure 2B), were not significantly different in $20 \%$ versus $2 \%$ oxygen (Figure $3 F$ ).

\section{Low 0xygen Tension Promotes pcEVT and Inhibits STB Differentiation in an HIF-Dependent Manner}

To determine whether an intact and functioning HIF complex is required for differentiation of primary vCTBs toward pcEVTs, we transduced isolated CTBs with lentivirus expressing either ARNT-specific or a negative control (scramble) shRNA. Efficiency of ARNT knockdown was assessed by Western blot (Figure 4A). ARNT was expressed in isolated CTBs (day 0) and in scrambleshRNA-transduced cells, cultured for 4 days in both $20 \%$ and $2 \%$ oxygen, but was significantly down-regulated in shARNT-transduced cells. HIF1 $\alpha$, on the other hand, was not present in freshly isolated vCTBs, but was up-regulated on culture in $2 \%$ oxygen, and more significantly so, in shARNT-transduced cells (Figure 4A). No apoptosis was noted in cells cultured in either condition, or after ARNT knockdown (Supplemental Figure S5). Down-regulation of transcripts for ARNT and various HIF target genes, including SLC2A1, GAPDH, and ANKRD37, in shARNTtransduced cells was confirmed by microarray analysis (Figure 4B). Microarray analysis also showed induction of EVT-associated markers (HLAG, TEAD2, and ASCL2) and down-regulation of STB markers (CGA and CGB) in 2\% oxygen; both of these effects were attenuated in shARNTtransduced cells. To further assess the effect of ARNT knockdown on vCTB differentiation, we evaluated both the expression and functional secretion of specific markers. We found that, with ARNT knockdown, the hypoxia-induced increases of both the percentage of $\mathrm{HLA}_{-} \mathrm{G}^{+}$cells and MMP2 secretion were attenuated (Figure 4, C and D). In addition, hypoxia-induced reduction of hCG secretion (Figure 4E) and syncytialization (Figure 4F) were also partially abrogated by knockdown of ARNT. Finally, shARNT-transduced vCTBs showed reduced expression of

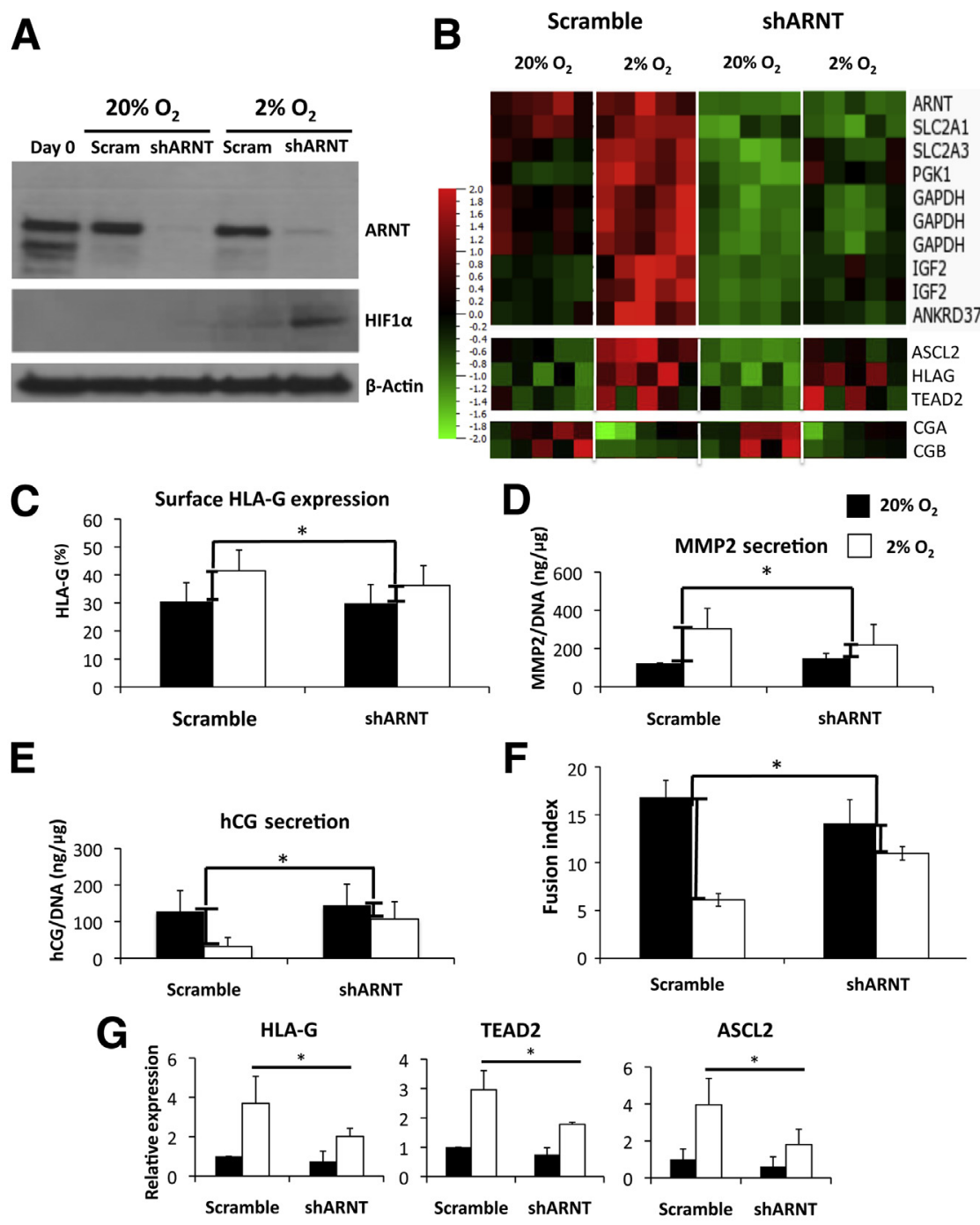

Figure 4 Hypoxia induces proximal column extravillous trophoblast ( $p c E V T$ ) differentiation in a hypoxia-inducible factor (HIF) complex-dependent manner. A: Aryl hydrocarbon receptor nuclear translocator (ARNT) and HIF1 $\alpha$ Western blots of lysates from freshly isolated cytotrophoblasts (CTBs) (day 0 ) and CTBs transduced with lentivirus expressing either scramble (Scram) shRNA or ARNTspecific shRNA, then cultured in $20 \%$ or $2 \% \mathrm{O}_{2}$ for 4 days. Actin was used as loading control. B: Gene expression of ARNT and HIF complex targets, EVTassociated genes (HLAG, TEAD2, and ASCL2), and syncytiotrophoblast-associated genes (CGA and CGB) in scramble or shARNT transduced cultured CTBs. C: Surface expression of HLA-G, analyzed by flow cytometry, of scramble- and shARNT-transduced cultured CTBs. D: Matrix metalloproteinase 2 (MMP2) secretion of scramble and shARNT-transduced cultured CTBs, normalized to DNA content. E: Human chorionic gonadotropin ( $\mathrm{hCG}$ ) secretion of scramble and shARNT-transduced cultured CTBs, normalized to DNA content. F: Fusion index of scramble and shARNT-transduced cultured CTBs, under $20 \%$ and $2 \%$ oxygen, calculated after staining with phalloidin and DAPI. G: Quantitative RT-PCR analysis of EVTassociated genes in RNA extracted from scramble and shARNT-transduced cultured CTBs. Values adjusted to freshly isolated cells (day 0 ) and normalized to 18 S ribosomal RNA. $n=3(\mathbf{F}) ; n=5(\mathbf{G}) .{ }^{*} P<0.05$. 
pcEVT-associated transcripts, including HLAG, TEAD2, and ASCL2 (Figure 4G).

\section{RNA Profiling Reveals Distinct Patterns of HIF-}

Dependent and HIF-Independent Gene Expression under Hypoxia

We subjected the CTBs, transduced with scramble or ARNT shRNA-expressing lentivirus, and cultured in $20 \%$ or $2 \%$ oxygen, to microarray-based gene expression analysis. Within each group, we focused on genes that were significantly up-regulated only after culture in $2 \%$ oxygen. We determined that 747 genes were significantly up-regulated in $2 \%$ oxygen in the presence of ARNT, whereas only 223 genes were significantly up-regulated in $2 \%$ oxygen in the ARNT knockdown cells (Figure 5). Of the 747 genes that were up-regulated in response to hypoxia in the presence of
ARNT, 588 (79\%) were no longer up-regulated with ARNT knockdown, and were considered to be HIF dependent (Figure 5); only 159 (21\%) remained up-regulated in the ARNT knockdown cultures and were considered to be HIF independent (Figure 5).

Next, we compared these 588 HIF-dependent and 159 HIF-independent hypoxia-inducible genes (Supplemental Table S3) to the gene expression profiles of sorted vCTBs $\left(\mathrm{EGFR}^{\text {high }} / \mathrm{HLAG}^{-}\right)$versus sorted pcEVTs $\left(\mathrm{EGFR}^{\text {low }} /\right.$ $\mathrm{HLAG}^{+}$). We found that both the HIF-dependent and HIFindependent groups shared the most genes with sorted pcEVT (21\% and $9 \%$ of pcEVT-associated genes, versus $1 \%$ and $0.5 \%$ of vCTB-associated genes, respectively). We then characterized the potential role(s) for the HIFdependent subset of hypoxia-inducible genes by subjecting them to functional enrichment analysis (Metascape), and to pathway analysis using IPA. The top 10 most significantly

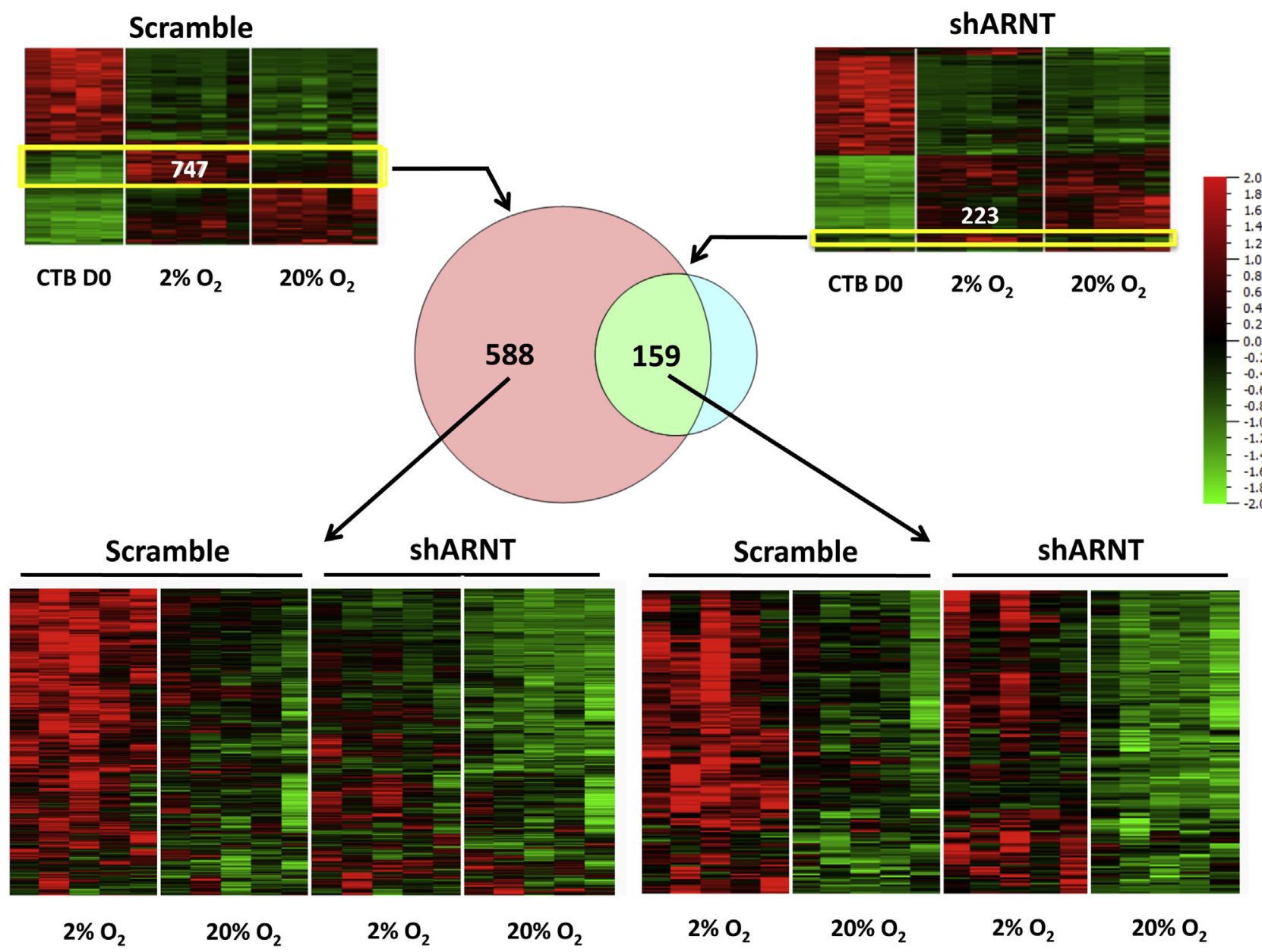

Figure 5 Analysis of hypoxia-inducible factor (HIF)-dependent hypoxia-inducible genes in cultured cytotrophoblasts (CTBs). Gene expression patterns in Scramble or shARNT-transduced cultured villous CTBs ( $v C T B s)$, compared to freshly isolated vCTBs. We performed statistical analysis ( $v<0.01$, multigroup comparison q < 0.05) on Scramble and shARNT-transduced cells, separately. Genes up-regulated in $2 \% 0_{2}$ in each group are bracketed in yellow: 747 genes in Scramble and 223 genes in shARNT-transduced cells. The overlap between these two gene groups is shown in the Venn diagram. One hundred fifty-nine genes remain up-regulated in the absence of aryl hydrocarbon receptor nuclear translocator (ARNT) and are labeled as HIF independent. Five hundred eighty-eight genes are lost (no longer up-regulated) in the absence of ARNT and labeled as HIF dependent. Heat maps below the Venn diagram show gene expression patterns of the 588 HIF-dependent (left two panels) and the 159 HIF-independent (right two panels) genes in both Scramble and shARNT-transduced samples. D0, day zero. 
enriched GO groups and top 10 pathways are listed in Supplemental Figure S6. Reassuringly, the most significantly enriched GO term was hypoxia. Other functions include cell adhesion and cytoskeletal remodeling, with multiple integrin and integrin-associated pathways. Interestingly, one of the pathways identified by IPA analysis was ILK signaling, a pathway similarly represented in the same analysis of pcEVT signature genes (Supplemental Figure S1). ILK is a known HIF complex-regulated gene with a strong role in promotion of epithelial-mesenchymal transition (EMT) in cancer cells. ${ }^{26}$ We first evaluated the expression of ILK itself. ILK protein was expressed specifically in EVT in the first-trimester placenta (Figure 6A). Although RNA and protein levels were not significantly changed after culture (Figure 6B and data not shown), protein levels were significantly reduced after ARNT knockdown (Figure 6B). We next inspected the members of the ILK pathway gene list in IPA, which were induced by hypoxia in an HIF-dependent manner. Among these genes, we identified genes associated with both remodeling of the actin cytoskeleton (cofilin/CFL1, paxillin/PXN, and RHOA) and with ILK-mediated EMT ( $\beta$-parvin/PARVB)
A
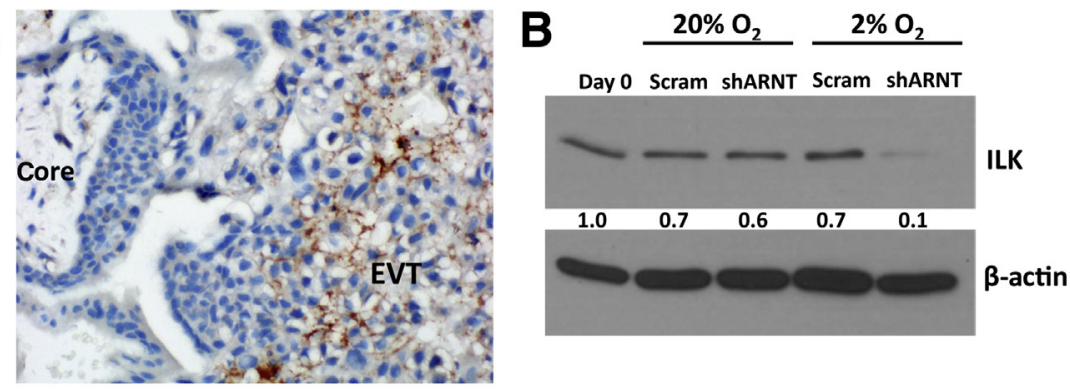

C Scramble
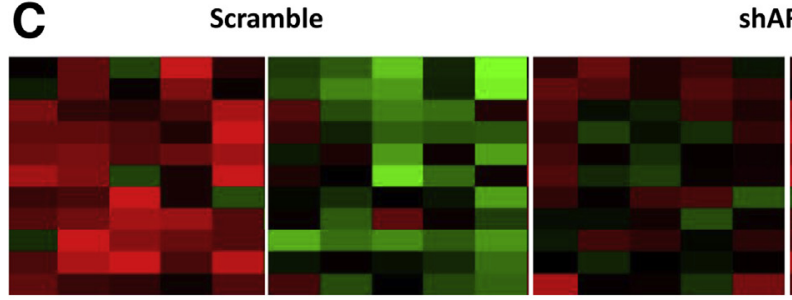

ShARNT

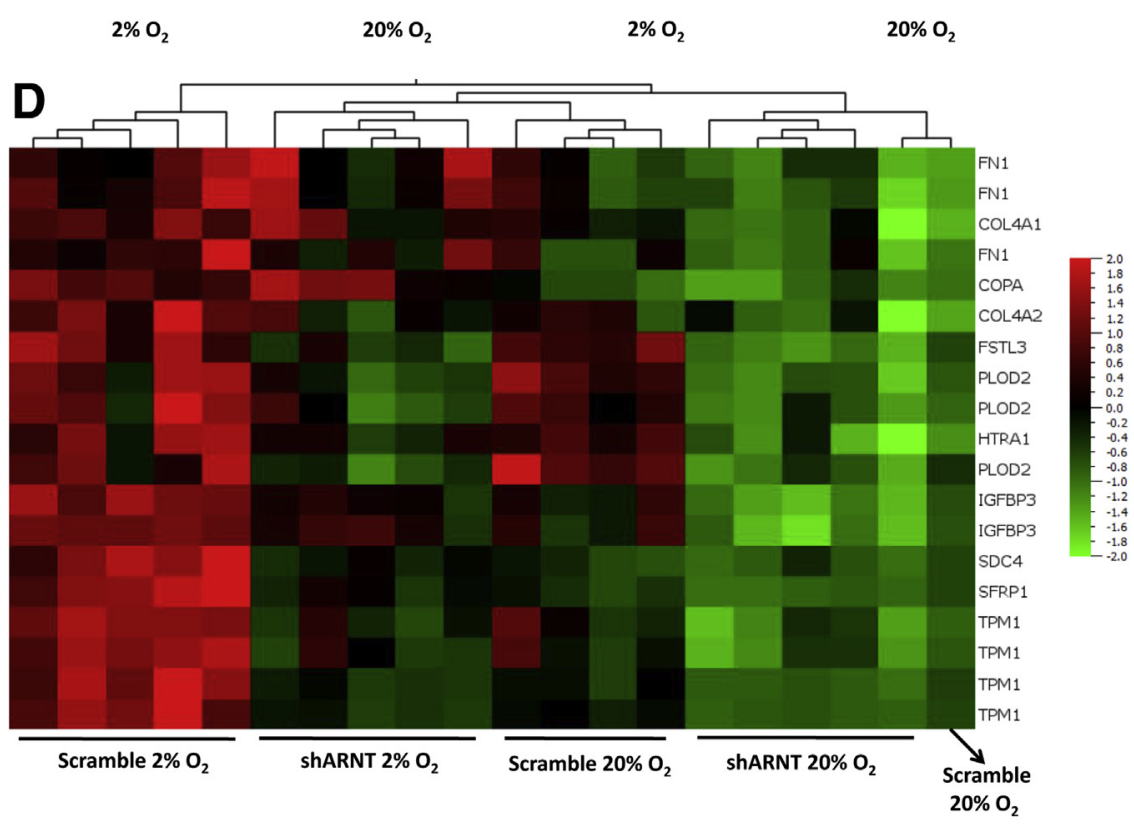

E

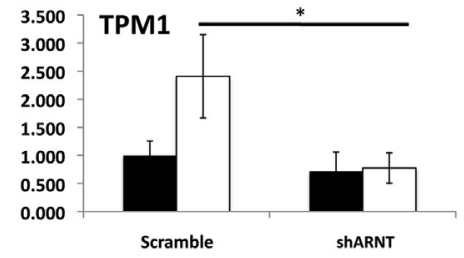

$\left.\begin{array}{l}5.000 \\ 4.000 \\ 3.000 \\ 2.000 \\ 1.000 \\ 0.000\end{array}\right]$

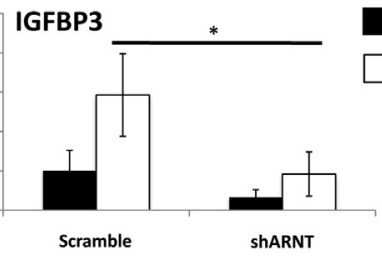

Figure 6 Integrin-linked kinase (ILK) pathway in cultured cytotrophoblasts (CTBs). A: ILK immunostaining of first-trimester placental tissue. Villous core and extravillous trophoblast (EVT) are labeled. B: ILK Western blot of lysates from freshly isolated CTBs (day 0) and CTBs transduced with lentivirus expressing either scramble (Scram) shRNA or ARNT-specific shRNA, then cultured in $20 \%$ or $2 \% \mathrm{O}_{2}$ for 4 days. Actin served as loading control. Numbers under the ILK blot indicate relative protein expression, by densitometry, normalized to actin and then to day 0 . The expression of ILK is drastically reduced in shARNTtransduced samples, but only when cultured in $2 \%$ $0_{2}$. C: ILK pathway-associated genes differentially expressed in cultured villous CTBs under indicated conditions. Note that the listed genes are most highly expressed in scramble-shRNA-transduced cells cultured in $2 \% \mathrm{O}_{2}$, and are down-regulated both in 20\% $\mathrm{O}_{2}$ and after aryl hydrocarbon receptor nuclear translocator (ARNT) knockdown. D: Hierarchical clustering, using differentially expressed epithelial-mesenchymal transition (EMT)-associated genes, separates scrambleshRNA-transduced CTB cultured in $2 \% \mathrm{O}_{2}$ from the other three groups of cells (both groups of CTBs cultured in $20 \% \mathrm{O}_{2}$, and $A R N T$-shRNA-transduced CTBs cultured in $\left.2 \% \mathrm{O}_{2}\right)(v<0.01$, multigroup comparison $\mathrm{q}<0.05)$. E: Validation of changes in expression of two EMT-associated genes, TPM1 and IGFBP3. Values adjusted to scramble-shRNAtransduced CTB cultured in $20 \% \mathrm{O}_{2}$, and normalized to 18 S ribosomal RNA. $n=3(\mathrm{E}) .{ }^{*} P<0.05$. Original magnification, $\times 200(A)$. 
(Figure 6C). Other EMT-associated genes also showed a distinct hypoxia-induced HIF-dependent pattern of expression (Figure 6D), which we confirmed by real-time quantitative PCR (Figure 6E). These results suggest that the HIF complex may promote differentiation of pcEVT through maintenance of ILK and ILK-induced EMT.

\section{Discussion}

This study evaluated the first step in differentiation of villous cytotrophoblast (vCTB) into $\mathrm{HLA}^{-\mathrm{G}^{+}}$proximal column extravillous trophoblast (pcEVT). A few previous studies used similar microarray-based gene expression profiling to evaluate EVT-specific gene signatures. ${ }^{27-29}$ However, two of these studies used cultured cells or explants, thereby introducing potential culture-induced artifact and/or evaluating potentially later stages of EVT differentiation. ${ }^{27,28}$ A third study evaluated the EVT gene signature, but with a focus on their interaction with the maternal immune system. ${ }^{29}$ By sorting $\mathrm{EGFR}^{\text {high }} / \mathrm{HLAG}^{-}$and $\mathrm{EGFR}^{\text {low }} / \mathrm{HLAG}^{+}$cells directly from digested villous tissue of early gestation placentas, we aimed to evaluate the first step toward differentiation of VCTB into the fully invasive EVT, focusing on the changes in regulatory transcription factors. Differentiation into EVT takes place in trophoblast cell columns, in anchoring villi of the early placenta, ${ }^{3}$ and, as we have previously found, is characterized by loss of p63, a transcription factor expressed exclusively in $\mathrm{VCTB}$, and lost quickly when these cells are removed from the underlying villous mesenchyme, either in vivo ${ }^{30}$ or in vitro. ${ }^{31}$ We identified multiple transcription factors up-regulated quickly during the transition into pcEVT, including two previously described factors, ASCL2 and GCM1. ASCL2 was originally characterized in the mouse, shown to be required for proper development of the placenta and particularly of the spongiotrophoblast, ${ }^{32,33}$ and later found to be expressed in EVT in the human placenta and maintained in CTB cultured in $2 \%$ oxygen. ${ }^{34,35}$ Herein, we confirmed its expression in EVT by in situ hybridization and its up-regulation on EVT differentiation of primary $\mathrm{VCTB}$ in vitro.

After ASCL2, the most highly expressed pcEVT-specific transcription factor was TEAD2. This protein is a member of the TEA domain family of transcription factors; the best known member of this family in the context of trophoblast differentiation in mice is Tead4, whose association with Yap1 and induction of $\mathrm{Cdx} 2$ is one of the earliest events in establishment of trophectoderm in mice. ${ }^{36,37}$ In fact, we noted enrichment of TEAD4 mRNA in the vCTB fraction, but also discovered TEAD2 as a novel pcEVT-associated transcription factor. Although a specific function for TEAD2 has not yet been identified, along with other TEA domain proteins, it has been shown to play a role in both cell growth and promotion of $\mathrm{EMT}^{38}$; the latter pathway has been implicated in differentiation of EVT in the human placenta (see below).
Other transcription factors identified in our sorted pcEVT population included TCF4, a Wnt-inducible factor, previously identified as a marker of human EVT, ${ }^{5,39}$ and GCM1, a transcription factor originally described as a labyrinth (villous) trophoblast-specific marker, required for branching morphogenesis, in the mouse placenta. ${ }^{40,41}$ Although more is known about its expression in villous trophoblast, where it regulates expression of SYNCYTIN genes, ${ }^{42,43}$ GCM1 has also previously been localized to EVT. ${ }^{44,45}$ We also noted high levels of GCM1 RNA in both STB and EVT, and comparatively lower levels in $\mathrm{VCTB}$; that GCM1 induction is involved in differentiation into both lineages was further confirmed on in vitro differentiation of vCTB, where GCM1 levels were equally increased in $20 \%$ and $2 \%$ oxygen.

Finally, HIF1A was another transcription factor enriched in the pcEVT fraction. This finding, along with the known role of the HIF complex in differentiation of the rodent EVT lineage (spongiotrophoblast and trophoblast giant cells), led us to further evaluate the role of oxygen tension during induction of the EVT lineage. We noted induction of HIF1A at the RNA level, in pcEVT in situ, in freshly isolated pcEVT, and following in vitro culture of vCTB in low oxygen; a similar induction of HIF1A RNA takes place during differentiation of mouse trophoblast stem cells into spongiotrophoblast/trophoblast giant cell lineages in vitro. ${ }^{16}$ That the protein was not abundantly expressed in pcEVT in situ is likely because of rapid degradation of this protein after exposure to room air; after vCTB culture in low oxygen, the protein was stabilized and easily detectable by Western blot.

Our findings on the effect of low oxygen on CTB may appear to diverge from the literature; however, in fact, there is much agreement between our results and other publications. That low oxygen (2\%) increases the proportion of HLA-G ${ }^{+}$cells in the cell column of first-trimester explants can be clearly seen in the study by Genbacev et $\mathrm{al}^{7}$; however, these cells were referred to as cytotrophoblast and the data interpreted as no change in level of HLA-G expression in the individual cells, on the basis of immunostaining. Subsequent studies of similar gestation explants by Caniggia et $\mathrm{al}^{10}$ showed expansion of integrin- $\alpha_{5} /$ ITGA $5^{+}$ cell column cells in low oxygen (3\%), in contrast to explants maintained in $20 \%$ oxygen. Most similar to our experimental model of isolated primary cytotrophoblast, however, is the study by Robins et al, ${ }^{12}$ showing that although isolated CTB fused and formed a syncytium at $20 \%$ oxygen, under low oxygen conditions (1\%), they remained mononuclear and instead expressed HLA-G abundantly. Similar to the latter study, our results point to high oxygen promoting villous trophoblast differentiation, and low oxygen directing differentiation along the extravillous pathway. Our results further expand on the Robins et $\mathrm{al}^{12}$ study, showing that an intact HIF complex is required, both for inhibition of villous differentiation and promotion of the EVT lineage.

Although this exciting new finding matches with rodent data on HIF dependence of the EVT lineage specification, it does not resolve the role of oxygen tension in trophoblast 
invasion. In rodents, not only has HIF been shown to be required for specification of this lineage, ${ }^{14-16,18}$ low oxygen and stabilization of HIF promote the invasive properties of these cells, leading to greater remodeling of uterine spiral arteries. ${ }^{17,18}$ Such in vivo promotion of trophoblast invasion by low oxygen has also been shown in rhesus monkeys, where aortic strictures increased the depth of invasion by interstitial EVT, although no change in endovascular invasion was observed. ${ }^{46}$ In vitro experiments, however, using both explants and isolated CTB from first-trimester human placental tissues, point to inhibition of trophoblast invasion under low oxygen, using integrin $\alpha_{1}$ /ITGA 1 as a surface marker of differentiated, invasive EVT and Matrigel invasion as a functional assay. ${ }^{7-11}$ It is possible that early during implantation, low oxygen initiates differentiation of the EVT lineage, and even promotes proliferation of cells with this proximal column phenotype, but that a gradient toward higher oxygen levels promotes maturation of these cells, into fully differentiated, invasive EVT. Future experiments will need to test this hypothesis, using either an explant system with various oxygen gradients or isolated cells, which can be differentiated into early EVT, then replated to complete maturation and test invasive ability at various oxygen tensions.

Similarly, our current study does not fully resolve the role of oxygen tension on trophoblast proliferation. In fact, previous studies have also noted increased proliferation of primary trophoblast under low oxygen, particularly in the context of first-trimester explants, ${ }^{7,10}$ but also in isolated CTBs. ${ }^{8,47}$ As in our previous study, ${ }^{31}$ and similar to results from other groups, ${ }^{29}$ we did not observe any proliferation of isolated CTBs, even at early time points after plating. However, it is possible that in vivo, in addition to promotion of pcEVT differentiation, low oxygen tension also promotes proliferation of $\mathrm{vCTB}$ and/or pcEVT, before differentiation into more mature EVTs.

Our results also point to the initial differentiation of vCTB into pcEVT having features in common with EMT. Although previous studies have focused on changes in expression of specific genes during the CTB-to-EVT transition, ${ }^{48,49}$ our study evaluated global gene expression changes in these two populations, then applied gene ontology and pathway analysis to identify changes in expression patterns of genes with similar functions. This led to the identification of EMT, along with many associated pathways involving cytoskeletal remodeling and cell adhesion. One of these was a pathway regulated by ILK, which was also found to be induced during pcEVT differentiation under low oxygen, in an HIF-dependent manner. ILK was originally discovered as a component of the focal adhesion kinase and has since been found to play numerous roles during embryonic development and tissue homeostasis. ${ }^{50,51}$ Although expression of ILK itself was not induced in the cells we used under low oxygen, its maintenance under these culture conditions appeared to be HIF dependent. In addition, multiple ILK pathway-associated genes, including cofilin $(C F L 1)$ and $\beta$-parvin $(P A R V B)$, were induced by low oxygen, also in an HIF-dependent manner.

The association of the ILK pathway with EVT differentiation is interesting in the context of the specific type of EMT occurring in the human placenta, which has been described as partial EMT. This is because EVT differentiation does not appear to be accompanied by complete loss of epithelial markers (eg, cytokeratin 7), nor the gain of hallmark mesenchymal markers (eg, vimentin). ${ }^{48,49,52}$ In fact, differentiation into endovascular EVT is even accompanied by reactivation of E-cadherin expression. ${ }^{53}$ In our study, we found the initial step in EVT differentiation to be associated with a high expression of TEAD2, a transcription factor shown to promote EMT. ${ }^{38}$ Even more interesting, however, was the involvement of hypoxia/HIF-regulated ILK pathway, which has also been shown to be a hallmark of cancer stem cells. Cancer stem cells are thought to be a subpopulation of cells within a tumor, maintained in a hypoxic microenvironment, and characterized by an EMTlike phenotype. ${ }^{54}$ ILK plays a role in maintenance of these cancer stem cells by linking integrins to the underlying actin cytoskeleton via $\beta$-parvin and cofilin, ${ }^{55}$ genes within the ILK pathway that were also up-regulated in pcEVT. Given that these cells are precursors to the highly invasive interstitial and endovascular EVT, we propose that proximal column EVTs are akin to cancer stem cells, and could potentially be studied as a model in this context.

In summary, we have presented a detailed molecular profile of the first stage of EVT differentiation in the human placenta and determined that low oxygen promotes this lineage in an HIF-dependent manner. In future studies, we plan to dissect out the mechanisms by which hypoxiainduced EMT induces EVT differentiation, specifically focusing on the role of the newly identified transcription factors, such as TEAD2, in this context.

\section{Acknowledgment}

M.M.P. is the guarantor of this work, had full access to all data, and takes responsibility for the integrity of the data and the accuracy of the data analysis.

\section{Supplemental Data}

Supplemental material for this article can be found at http://dx.doi.org/10.1016/j.ajpath.2016.11.018.

\section{References}

1. Guttmacher AE, Maddox YT, Spong CY: The Human Placenta Project: placental structure, development, and function in real time. Placenta 2014, 35:303-304

2. Burton GJ, Jauniaux E: What is the placenta? Am J Obstet Gynecol 2015, 213(Suppl 4):S6e1. S6-S8

3. James JL, Carter AM, Chamley LW: Human placentation from nidation to 5 weeks of gestation, part I: what do we know about 
formative placental development following implantation? Placenta 2012, 33:327-334

4. Jauniaux E, Watson AL, Hempstock J, Bao YP, Skepper JN, Burton GJ: Onset of maternal arterial blood flow and placental oxidative stress. Am J Pathol 2000, 157:2111-2122

5. Knöfler M, Pollheimer J: Human placental trophoblast invasion and differentiation: a particular focus on Wnt signaling. Front Genet 2013, 4:190

6. Fisher SJ: Why is placentation abnormal in preeclampsia? Am J Obstet Gynecol 2015, 213(Suppl 4):S115-S122

7. Genbacev O, Zhou Y, Ludlow JW, Fisher SJ: Regulation of human placental development by oxygen tension. Science 1997, 277: $1669-1672$

8. Genbacev O, Joslin R, Damsky CH, Polliotti BM, Fisher SJ: Hypoxia alters early gestation human cytotrophoblast differentiation/invasion in vitro and models the placental defects that occur in preeclampsia. $\mathrm{J}$ Clin Invest 1996, 97:540-550

9. Genbacev O, Krtolica A, Kaelin W, Fisher SJ: Human cytotrophoblast expression of the von Hippel-Lindau protein is downregulated during uterine invasion in situ and upregulated by hypoxia in vitro. Dev Biol 2001, 233:526-536

10. Caniggia I, Mostachfi H, Winter J, Gassmann M, Lye SJ, Kuliszewski M, Post M: Hypoxia-inducible factor-1 mediates the biological effects of oxygen on human trophoblast differentiation through TGFbeta(3). J Clin Invest 2000, 105:577-587

11. Caniggia I, Winter J, Lye SJ, Post M: Oxygen and placental development during the first trimester: implications for the pathophysiology of pre-eclampsia. Placenta 2000, 21 Suppl A:S25-S30

12. Robins JC, Heizer A, Hardiman A, Hubert M, Handwerger S: Oxygen tension directs the differentiation pathway of human cytotrophoblast cells. Placenta 2007, 28:1141-1146

13. Patel J, Landers K, Mortimer RH, Richard K: Regulation of hypoxia inducible factors (HIF) in hypoxia and normoxia during placental development. Placenta 2010, 31:951-957

14. Adelman DM, Gertsenstein M, Nagy A, Simon MC, Maltepe E: Placental cell fates are regulated in vivo by HIF-mediated hypoxia responses. Genes Dev 2000, 14:3191-3203

15. Cowden Dahl KD, Fryer BH, Mack FA, Compernolle V, Maltepe E, Adelman DM, Carmeliet P, Simon MC: Hypoxia-inducible factors 1alpha and 2alpha regulate trophoblast differentiation. Mol Cell Biol 2005, 25:10479-10491

16. Maltepe E, Krampitz GW, Okazaki KM, Red-Horse K, Mak W, Simon MC, Fisher SJ: Hypoxia-inducible factor-dependent histone deacetylase activity determines stem cell fate in the placenta. Development 2005, 132:3393-3403

17. Rosario GX, Konno T, Soares MJ: Maternal hypoxia activates endovascular trophoblast cell invasion. Dev Biol 2008, 314: 362-375

18. Chakraborty D, Rumi MA, Konno T, Soares MJ: Natural killer cells direct hemochorial placentation by regulating hypoxia-inducible factor dependent trophoblast lineage decisions. Proc Natl Acad Sci U S A 2011, 108:16295-16300

19. James JL, Stone PR, Chamley LW: The regulation of trophoblast differentiation by oxygen in the first trimester of pregnancy. Hum Reprod Update 2006, 12:137-144

20. Caniggia I, Winter JL: Adriana and Luisa Castellucci Award lecture 2001: hypoxia inducible factor-1: oxygen regulation of trophoblast differentiation in normal and pre-eclamptic pregnancies-a review. Placenta 2002, 23 Suppl A:S47-S57

21. Ji L, Brkić J, Liu M, Fu G, Peng C, Wang YL: Placental trophoblast cell differentiation: physiological regulation and pathological relevance to preeclampsia. Mol Aspects Med 2013, 34:981-1023

22. Zhou Y, Genbacev O, Damsky CH, Fisher SJ: Oxygen regulates human cytotrophoblast differentiation and invasion: implications for endovascular invasion in normal pregnancy and in pre-eclampsia. $\mathrm{J}$ Reprod Immunol 1998, 39:197-213
23. Wang F, Flanagan J, Su N, Wang LC, Bui S, Nielson A, Wu X, Vo HT, Ma XJ, Luo Y: RNAscope: a novel in situ RNA analysis platform for formalin-fixed, paraffin-embedded tissues. J Mol Diagn 2012, 14:22-29

24. Plessl K, Haider S, Fiala C, Pollheimer J, Knöfler M: Expression pattern and function of Notch2 in different subtypes of first trimester cytotrophoblast. Placenta 2015, 36:365-371

25. Bjørn SF, Hastrup N, Larsen JF, Lund LR, Pyke C: Messenger RNA for membrane-type 2 matrix metalloproteinase, MT2-MMP, is expressed in human placenta of first trimester. Placenta 2000, 21: 170-176

26. Chou CC, Chuang HC, Salunke SB, Kulp SK, Chen CS: A novel HIF- $1 \alpha$-integrin-linked kinase regulatory loop that facilitates hypoxia-induced HIF-1 $\alpha$ expression and epithelial-mesenchymal transition in cancer cells. Oncotarget 2015, 6:8271-8285

27. Bilban $M$, Haslinger $P$, Prast $J$, Klinglmüller $F$, Woelfel $T$, Haider S, Sachs A, Otterbein LE, Desoye G, Hiden U, Wagner O, Knöfler M: Identification of novel trophoblast invasion-related genes: heme oxygenase-1 controls motility via peroxisome proliferator-activated receptor gamma. Endocrinology 2009, 150: $1000-1013$

28. Apps R, Sharkey A, Gardner L, Male V, Trotter M, Miller N, North R, Founds S, Moffett A: Genome-wide expression profile of first trimester villous and extravillous human trophoblast cells. Placenta 2011, 32:33-43

29. Tilburgs $\mathrm{T}$, Crespo ÂC, van der Zwan A, Rybalov B, Raj T, Stranger B, Gardner L, Moffett A, Strominger JL: Human HLA-G+ extravillous trophoblasts: immune-activating cells that interact with decidual leukocytes. Proc Natl Acad Sci U S A 2015, 112: 7219-7224

30. Lee Y, Kim KR, McKeon F, Yang A, Boyd TK, Crum CP, Parast MM: A unifying concept of trophoblastic differentiation and malignancy defined by biomarker expression. Hum Pathol 2007, 38: $1003-1013$

31. Li Y, Moretto-Zita M, Leon-Garcia S, Parast MM: p63 Inhibits extravillous trophoblast migration and maintains cells in a cytotrophoblast stem cell-like state. Am J Pathol 2014, 184: $3332-3343$

32. Guillemot F, Nagy A, Auerbach A, Rossant J, Joyner AL: Essential role of Mash-2 in extraembryonic development. Nature 1994, 371: $333-336$

33. Tanaka M, Gertsenstein M, Rossant J, Nagy A: Mash2 acts cell autonomously in mouse spongiotrophoblast development. Dev Biol 1997, 190:55-65

34. Alders M, Hodges M, Hadjantonakis AK, Postmus J, van Wijk I, Bliek J, de Meulemeester M, Westerveld A, Guillemot F, Oudejans C, Little P, Mannens M: The human Achaete-Scute homologue 2 (ASCL2,HASH2) maps to chromosome 11p15.5, close to IGF2 and is expressed in extravillus trophoblasts. Hum Mol Genet 1997, 6:859-867

35. Jiang B, Kamat A, Mendelson CR: Hypoxia prevents induction of aromatase expression in human trophoblast cells in culture: potential inhibitory role of the hypoxia-inducible transcription factor Mash-2 (mammalian achaete-scute homologous protein-2). Mol Endocrinol 2000, 14:1661-1673

36. Nishioka N, Inoue $\mathrm{K}$, Adachi K, Kiyonari H, Ota M, Ralston A, Yabuta N, Hirahara S, Stephenson RO, Ogonuki N, Makita R, Kurihara H, Morin-Kensicki EM, Nojima H, Rossant J, Nakao K, Niwa H, Sasaki H: The Hippo signaling pathway components Lats and Yap pattern Tead4 activity to distinguish mouse trophectoderm from inner cell mass. Dev Cell 2009, 16: $398-410$

37. Home P, Saha B, Ray S, Dutta D, Gunewardena S, Yoo B, Pal A, Vivian JL, Larson M, Petroff M, Gallagher PG, Schulz VP, White KL, Golos TG, Behr B, Paul S: Altered subcellular localization of transcription factor TEAD4 regulates first mammalian cell 
lineage commitment. Proc Natl Acad Sci U S A 2012, 109: $7362-7367$

38. Zhang H, Liu CY, Zha ZY, Zhao B, Yao J, Zhao S, Xiong Y, Lei QY, Guan KL: TEAD transcription factors mediate the function of TAZ in cell growth and epithelial-mesenchymal transition. J Biol Chem 2009, 284:13355-13362

39. Pollheimer J, Loregger T, Sonderegger S, Saleh L, Bauer S, Bilban M, Czerwenka K, Husslein P, Knöfler M: Activation of the canonical wingless/T-cell factor signaling pathway promotes invasive differentiation of human trophoblast. Am J Pathol 2006, 168: $1134-1147$

40. Basyuk E, Cross JC, Corbin J, Nakayama H, Hunter P, NaitOumesmar B, Lazzarini RA: Murine Gcm1 gene is expressed in a subset of placental trophoblast cells. Dev Dyn 1999, 214:303-311

41. Anson-Cartwright L, Dawson K, Holmyard D, Fisher SJ, Lazzarini RA, Cross JC: The glial cells missing-1 protein is essential for branching morphogenesis in the chorioallantoic placenta. Nat Genet 2000, 25:311-314

42. Baczyk D, Drewlo S, Proctor L, Dunk C, Lye S, Kingdom J: Glial cell missing-1 transcription factor is required for the differentiation of the human trophoblast. Cell Death Differ 2009, 16:719-727

43. Lin $\mathrm{C}$, Lin M, Chen H: Biochemical characterization of the human placental transcription factor GCMa/1. Biochem Cell Biol 2005, 83: 188-195

44. Baczyk D, Satkunaratnam A, Nait-Oumesmar B, Huppertz B, Cross JC, Kingdom JC: Complex patterns of GCM1 mRNA and protein in villous and extravillous trophoblast cells of the human placenta. Placenta 2004, 25:553-559

45. Janatpour MJ, Utset MF, Cross JC, Rossant J, Dong J, Israel MA, Fisher SJ: A repertoire of differentially expressed transcription factors that offers insight into mechanisms of human cytotrophoblast differentiation. Dev Genet 1999, 25:146-157
46. Zhou Y, Chiu K, Brescia RJ, Combs CA, Katz MA, Kitzmiller JL, Heilbron DC, Fisher SJ: Increased depth of trophoblast invasion after chronic constriction of the lower aorta in rhesus monkeys. Am J Obstet Gynecol 1993, 169:224-229

47. Alsat E, Wyplosz P, Malassiné A, Guibourdenche J, Porquet D, Nessmann C, Evain-Brion D: Hypoxia impairs cell fusion and differentiation process in human cytotrophoblast, in vitro. J Cell Physiol 1996, 168:346-353

48. Vićovac L, Aplin JD: Epithelial-mesenchymal transition during trophoblast differentiation. Acta Anat (Basel) 1996, 156:202-216

49. DaSilva-Arnold S, James JL, Al-Khan A, Zamudio S, Illsley NP: Differentiation of first trimester cytotrophoblast to extravillous trophoblast involves an epithelial-mesenchymal transition. Placenta 2015, 36:1412-1418

50. Attwell S, Roskelley C, Dedhar S: The integrin-linked kinase (ILK) suppresses anoikis. Oncogene 2000, 19:3811-3815

51. Hannigan GE, McDonald PC, Walsh MP, Dedhar S: Integrin-linked kinase: not so "pseudo" after all. Oncogene 2011, 30:4375-4385

52. E Davies J, Pollheimer J, Yong HE, Kokkinos MI, Kalionis B, Knöfler M, Murthi P: Epithelial-mesenchymal transition during extravillous trophoblast differentiation. Cell Adh Migr 2016, 12:1-12

53. Floridon C, Nielsen O, Holund B, Sunde L, Westergaard JG, Thomsen SG, Teisner B: Localization of E-cadherin in villous, extravillous and vascular trophoblasts during intrauterine, ectopic and molar pregnancy. Mol Hum Reprod 2000, 6:943-950

54. Philip B, Ito K, Moreno-Sánchez R, Ralph SJ: HIF expression and the role of hypoxic microenvironments within primary tumours as protective sites driving cancer stem cell renewal and metastatic progression. Carcinogenesis 2013, 34:1699-1707

55. Shibue T, Brooks MW, Weinberg RA: An integrin-linked machinery of cytoskeletal regulation that enables experimental tumor initiation and metastatic colonization. Cancer Cell 2013, 24:481-498 